\title{
A decisional support system to quantify risk due to the transportation of dangerous substances
}

\author{
A. Romano \& G. Romano \\ TRR S.r.l., Osio Sotto, Bergamo, Italy
}

\begin{abstract}
The transportation of hazardous materials is a growing problem worldwide due to increasing transported volumes. In fact, as a consequence of industrial development, huge quantities of hazardous materials are yearly produced and obviously the production of them goes together with their transportation. Historical evidence has shown that accidents due to hazardous releases during transportation can lead to serious consequences as those created by fixed plants and therefore quantified risk analysis has to be carried out for transportation networks too. In this paper, a flexible decision support system is proposed to quantify risk due to different transportation of dangerous substances - road, rail, pipeline and inland waterways.

First, a brief discussion is given on methodology adopted for evaluating risk.

Then, the steps of the algorithm that has been implemented are sketched out to some details.

Finally a description of the software is given out. Supported by a GIS-data bank, where parameters of the different transport networks are geo-referenced (i.e. incident rate, number of vehicles/year), the software provides to quantify Individual and Population Risk. Some applications in relation to possible risk mitigation are discussed, as the influence of a new road or reducing transported quantity, thus confirming in this way a possible use of this instrument by the decision maker in territorial planning and emergency management.
\end{abstract}

Keywords: transportation, dangerous substances, risk analysis, road, GIS. 


\section{Introduction}

As a consequence of industrial development, large quantities of hazardous substances, such as raw materials, intermediate or final product and waste are moved through the transportation network by different means, such as road, rail, pipeline and inland waterways. In the last 15 years the scientific community has focused attention on the quantified risk analysis of hazardous material transportation.

Analyst has extended the techniques developed for fixed plants to these particular risk sources, and the tendency over recent years is to create a territorial planning instrument, thus combining risk analysis know how and Geographical Information System potentiality.

The scope of the paper is to present a methodology that has already been experimented in Italy; in Lombardia where the Public Authority has decided to create a decisional support system to quantify risks due to the transportation of dangerous substances.

The approach could be applied at a regional scale in other contests, and Lombardia represents a pilot study for planning risks about transportation. The study has been geared in relation to some critical indicators regarding Lombardia:

- about average concentration of company/activities (30 activities per $\mathrm{km}^{2}$; the highest in Italy)

- about industrial activities classified by Seveso laws: $25 \%$ of the country

- about transportation of dangerous substances. In Italy, 70,000,000 tons are transported by road and 5.000 .000 by rail. Lombardia represents $25 \%$ of the former and $50 \%$ of the latter.

\section{Risk management system adopted for evaluating risks due to transportation of dangerous substances at a regional scale}

A risk assessment analysis for a specific transportation may include:

- description of the transport stream (number of yearly loaded transport unit per substance or category)

- description of transport units

- description of the transport route

- description of the number of accidents and degree of traffic in order to determine accident frequencies

- description of ignition sources

- properties of transported substances

- terrain classification of the surroundings of transport route

- meteorological data

- population present in the surrounding area of transport route. 
In order to evaluate risk about transport and using Geographical Information System potentiality, a management system could be adopted for creating a flexible instrument for planning at a regional scale, thus combining state-of-theart guidelines and needs of the project. The scale of the study area needs a practical instrument for managing a large number of input. A possible approach is illustrated in a very synthetic block diagram in Figure 1. Before the risk evaluation, a full characterization of the transport flow may be made. Phase 1 corresponds to this data characterization before starting to quantify risks. A data bank has been constructed for the four transport system - road, rail, pipeline and inland waterways. In each data bank all data has been referred to the network with GIS. Road and rail has been characterized by those indicators:

- indicators about incident

- indicators about heavy and light traffic (not hazardous)

- indicators about hazardous transport

- indicators about population referred to the trait.

The approach has been guided by the need to characterize a trait of the network for evaluating risk/s in a specific point of the road (rail).

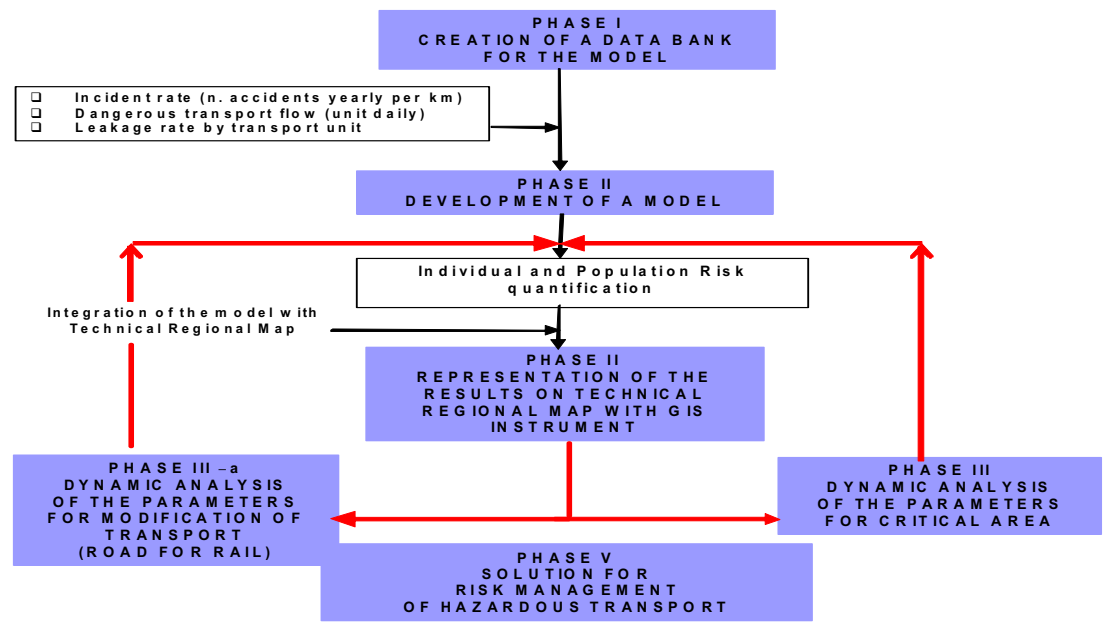

Figure 1: $\quad$ Synthetic block diagram for description of project phase.

Then, in Phase III the model and maps have been integrated.

The result is GIS software where, over a Technical Regional Map, a simulation for a specific road/rail/pipeline trait can be made.

In the Phase IV software has been implemented for dynamic analysis, such as the possibility to modify parameters in order to appreciate the sensibility of the output to the risks. 
For a specific area a variation can be made for:

- number of initial accident frequency;

- dangerous transport flow;

- leakage property.

Phase IV is dynamic analysis in order to quantifying the impact of a new road, or the effect of moving a certain quantity of dangerous substances from road to rail and vice versa. Dynamic analysis is a instrument for evaluating possible solutions for reduction of the risk/s and the effects of future scenarios about variation of the traffic. In Italy it is forecasted that transport will increase by $30 \%$. All these factors lead to Phase V where solutions for risk management of hazardous materials have been investigated.

\section{Development of a model for quantifying risk due to transportation of dangerous substances}

The parameters for quantifying risk due to the transportation if dangerous materials adopted in this study are now discussed.

Let us define:

- $\lambda=$ incident frequency of the selected trait (number of accidents yearly per $\mathrm{km})$

- $\quad \mathrm{L}=$ length of the trait $(\mathrm{km})$

- $\quad \mathrm{NT}=$ hazardous traffic flow (number of dangerous substances transported daily)

- $\mathrm{PK}=$ probability of release by transport unit

- $\quad \mathrm{PS}=$ probability of ignition of flammable substances

- $\quad \mathrm{PJ}=$ probability of certain meteorological data

- $\quad \mathrm{PW}=$ probability of terrain classification of the surrounding area of transport route (urban, rural and industrial)

- $\mathrm{A}=$ impact area $\left(\mathrm{km}^{2}\right)$

- $\mathrm{DW}=$ population in the surroundings associated to selected trait

- $\mathrm{FUG}=$ human shelter factor for escaping and protection.

About the first parameter, $\lambda$, the GIS data bank created for the project provides to give for a selected trait the number of the accident yearly per $\mathrm{km}$.

The hypothesis adopted for road transportation is that $\lambda$ is the initial frequency of serious damage to vessel per unit distance.

The initial accident frequency strongly depends on local factors. For that reason each kilometre of the road system has been characterized by a specific initial frequency.

By the way rail and pipeline streams have been characterized with a constant incident rate per $\mathrm{km}$.

- length of the selected trait $(\mathrm{km})$. 
Software allows one to identify on the Technical Map a certain length of the transport system. Minimum unit is one kilometre.

- hazardous traffic flow (number of dangerous substances transported daily).

In the selected length a very important parameter is the number of passages in a unit time of the dangerous substances inherent in the trait. A very long study has been carried out to determine in the investigated area of dangerous substances flow.

The identification of those flows in rail and pipeline streams has been made with a high degree of detail. In fact, in those systems, the initial and final point of the transported quantity is simply identified.

On the contrary in road transport more specific hypotheses have be made.

Despite its analysis complexity, a GIS data bank about hazardous material has been constructed concerning 9 Classes, defined by ADR, European agreement for the transportation of dangerous goods. In order to be brief, it was necessary to make a selection of certain dangerous substances.

- probability of release by transport unit PK.

The probability of a release by the vessel given an accident for the specific transport unit is based on the following loss of containment events:

- release of complete inventory $\left(20 \mathrm{~m}^{3}\right.$ for road vessel and $50 \mathrm{~m}^{3}$ for rail)

- release of $50 \%$ of inventory

- release of the $10 \%$ of inventory.

A distinction has been made between pressurized and atmospheric container. Let us define:

- $\mathrm{K}=0$ as no release

- $\mathrm{K}=1$ as $10 \%$ of inventory

- $\mathrm{K}=2$ as $50 \%$ of inventory

- $\mathrm{K}=3$ as release of the complete inventory.

The probabilities adopted for road containers are reported in Table 1.

- probability of ignition of flammable substances.

Table 1: $\quad$ Probability of release for road transport unit.

\begin{tabular}{|c|c|}
\hline PRESSURISED (\%) & ATMOSPHERIC (\%) \\
\hline $\mathrm{P}(\mathrm{K}=0)=99$ & $\mathrm{P}(\mathrm{K}=0)=90$ \\
\hline $\mathrm{P}(\mathrm{K}=1)=0.9$ & $\mathrm{P}(\mathrm{K}=1)=9$ \\
\hline $\mathrm{P}(\mathrm{K}=2)=0,07$ & $\mathrm{P}(\mathrm{K}=2)=0,7$ \\
\hline $\mathrm{P}(\mathrm{K}=3)=0,03$ & $\mathrm{P}(\mathrm{K}=3)=0,3$ \\
\hline
\end{tabular}

The events that have been considered are: toxic exposure, pool fire, jet fire, flash fire. For a given accident and for given quantity released a probability of ignition may be adopted for flammable substance. This data has been quantified with an events tree. 
- probability of certain meteorological data

Typical meteorological conditions have been investigated, in particular, Pasquill Stability Class F and D.

- probability of terrain classification of the surrounding of transport route (urban, rural and industrial).

A classification of the surroundings has been made for all transport networks. A GIS data bank, referring to the location, gives three probabilities, i.e. $30 \%$ arable land, $30 \%$ industrial area and $40 \%$ city and town.

- impact area $\left(\mathrm{km}^{2}\right)$.

The physical effects of the considered events are calculated.

- population in the surrounding area associated to examined trait.

For all networks, the number of people that could be exposed to the accident is calculated.

The criteria corresponds to a selection of 1 kilometre up and down in the area of the potential release, where not only residential population is included but also the potential human presence in schools, hospitals and offices.

- $\quad$ shelter factor for human presence.

In order to estimate physical effects to human beings and health some shelter factors have been considered, i.e. the possibility of escaping and being protected.

In conclusion, the Frequency (event/year) and Impact (number of people affected) is calculated within the following expressions:

$$
\begin{gathered}
\mathrm{F}(\mathrm{J}, \mathrm{s}, \mathrm{K}, \mathrm{W}, \mathrm{S})=\lambda * \mathrm{~L}^{*} \mathrm{NTs}^{*} \mathrm{PK}^{*} \mathrm{PS} * \mathrm{PJ}^{*} \mathrm{PW} \\
\mathrm{I}(\mathrm{So}, \mathrm{s}, \mathrm{J}, \mathrm{K}, \mathrm{S}, \mathrm{W})=\mathrm{A}(\mathrm{So}, \mathrm{J}, \mathrm{s}, \mathrm{K}) * \mathrm{DW}(\mathrm{W}) * \mathrm{FAT}(\mathrm{W}) *(1-\mathrm{FUG}(\mathrm{J}))
\end{gathered}
$$

Using a simple function for combining F and I, the Population Risk (affected yearly) takes on the following expression:

$$
\mathrm{R}(\mathrm{I}, \mathrm{J}, \mathrm{s}, \mathrm{K}, \mathrm{S}, \mathrm{W})=\mathrm{F}(\mathrm{J}, \mathrm{s}, \mathrm{K}, \mathrm{W}, \mathrm{S})^{*} \mathrm{I}(\mathrm{So}, \mathrm{J}, \mathrm{s}, \mathrm{K}, \mathrm{S}, \mathrm{W})
$$

In order to be brief, other details are omitted.

\section{The software: technical solution adopted}

The model and maps have been integrated. The result is GIS software where, over Technical Regional Map, a simulation for a specific road/rail/pipeline trait can be done.

An image of the use of this instrument is presented in Figure 2. The main characteristics are:

- it has been developed in an accessible standard and compatible with most commonly used operating systems

- it is equipped by user interface for selection of road,

- rail and pipeline stream

- the results will be geo-references into a Technical Regional Map

- consulting data bank associated to the selected trait; in particular, all input described in the present paper. 


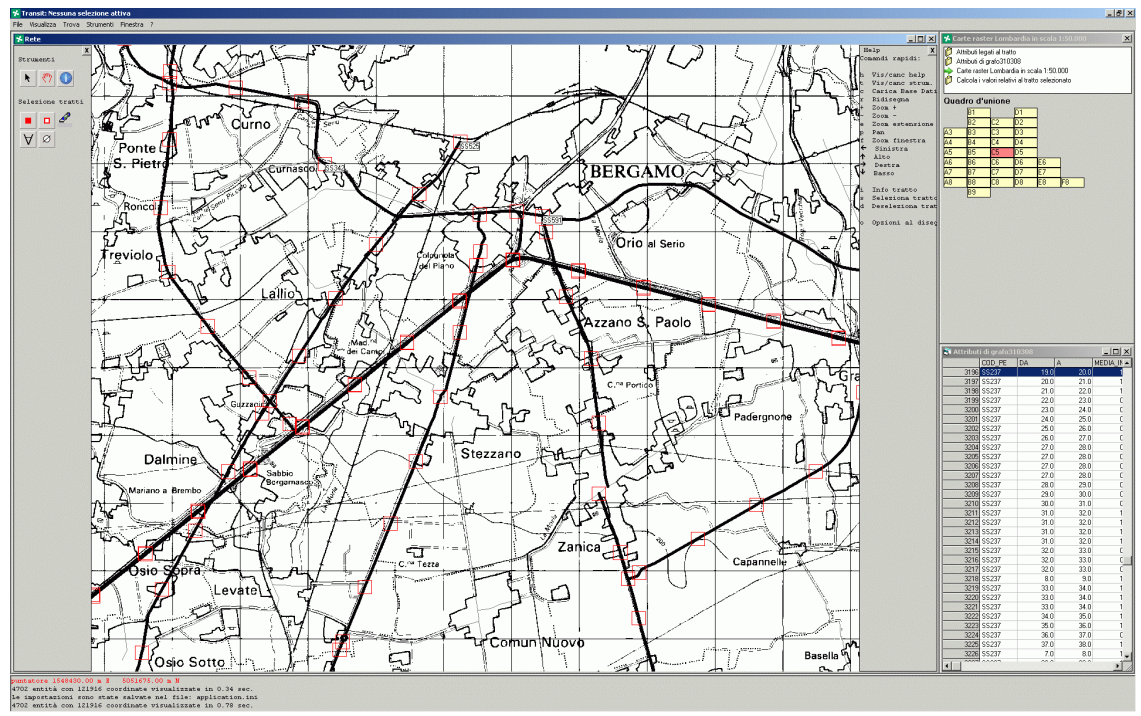

Figure 2: Zoom in of the area near Milan.

Table 2: $\quad$ List of the input for Tangenziale East Milan.

INPUT

\section{Highway A51 \\ Tangenziale East Milano}

number of selected trait:

length of the selected trait $(\mathrm{km})$

Incident rate [vehicle /year per km]

Vehicle

(average)

Heavy vehicle

(average)

8030

PW1 rural (average)

0

PW2 semi-rural

(average)

0.15

PW3 city

(average)

(average)

0.85

DW1 habitants $/ \mathrm{km} 2$

DW2 habitants $/ \mathrm{km} 2$

(average)

0

DW3 habitants $/ \mathrm{km} 2$

Ammonia

LPG

Ethylene Dioxide

Gasoline

Diesel

Liquid Oxygen

Hydrofluoric Acid

Sulphuric Acid

(average)

16219

30627

(vehicle/day) 30

(vehicle /day) 43

(vehicle/day) 14

(vehicle/day) 199

(vehicle/day) 199

(vehicle /day) 16

(vehicle /day) 16

(vehicle/day) 11 
An example of input and output is given for Tangenziale East of Milan in Table 3, one of the traits with a more elevated concentration of traffic and incident per day in all Europe.

The output concerned is presented in Table 3:

Table 3: $\quad$ Risk for the population for Highway A51 Tangenziale East Milan.

\begin{tabular}{|l|c|c|c|}
\hline \multicolumn{4}{|c|}{ RISK FOR THE POPULATION [people affected yearly] } \\
\hline & REVERSIBLE & $\begin{array}{c}\text { NOT } \\
\text { REVERSIBLE }\end{array}$ & LETALITY \\
\hline Urban area & $2.5 \mathrm{E}-1$ & $1.5 \mathrm{E}-1$ & $2.1 \mathrm{E}-2$ \\
\hline Semi-rural & $1.1 \mathrm{E}-1$ & $3.3 \mathrm{E}-2$ & $8.6 \mathrm{E}-3$ \\
\hline All area & $3.5 \mathrm{E}-1$ & $1.8 \mathrm{E}-1$ & $3 . \mathrm{E}-2$ \\
\hline
\end{tabular}

\section{Conclusions and future development}

The methodology chosen for this study allowed us to quantify risk for the transportation of dangerous materials. In this paper, for the examined trait, a simplified example for the valuation of Individual and Population risk has been proposed.

This information data could be automatically updated by Public Authority, who in turn could create a data bank for territorial planning. This data could be a valid support for subjects with different competence and role - such as Regions, Province and Local and Public authorities - especially when they have to handle the transportation of dangerous substances by road. Finally, the approach allows for:

- identifying the traits with great risks in different transport streams;

- a possible planning instrument for Public Authority for evaluating the impact of new road, expansion of existing network and make planning forecast for the next ten years (an increase of $30 \%$ has been estimated).

- a possible instrument for decision makers in order to evaluate the reduction of risk/s, such as restrictions on time/frames or trait deviations.

\section{References}

[1] Bello G.C, Romano A, Analisi dei rischi relativi al trasporto ferroviario di acido fluoridrico anidro, TRR Tecnologia Ricerca Rischi, Osio Sotto (BG), 1986.

[2] Istituto Nazionale di Statistica ISTAT - Settore Servizi, Conto nazionale delle infrastrutture e dei trasporti CNIT, Roma, 2006. 
[3] Leonelli P., Bonvicini S., Spadoni G., New detailed numerical procedures for calculating risk measures in hazardous materials transportation, Journal Haz. Mat, 71 (3), 423-437, 1998.

[4] TNO, Guideline for quantitative risk assessment 'Purple Book', CPR18E, Part 2, Committee for The Prevention of Disaster, The Hague, The Netherlands, 2005. 